The International Association for Social Science Information Service and Technology (IASSIST) invites your participation in its 32nd annual conference entitled Data in a World of Networked Knowledge on May 22-26, 2006 in Ann Arbor, Michigan. The conference will be preceded by workshops and followed by optional weekend activities in the Ann Arbor area. Details about the conference and the association may be found on the IASSIST website at: <http://www.iassistdata.org >

Proposals for papers, sessions and poster/demonstrations should be submitted by 16th January 2006.

The 2006 conference theme, Data in a World of Networked Knowledge, highlights the role of empirical data in a society that wishes not only to know itself, but also to build an enduring, interconnected storehouse of knowledge for learning and research. Once again IASSIST offers a time and place to explore, enlighten, and energize the participation of data professionals in the networked information world. We seek submissions of papers, poster/ demonstration sessions, and panel sessions on topics that address the full range of digital data life cycle issues, including those that focus on access, documentation, dissemination, preservation, data use and current empirical research activity.

Additional topics might also include information and statistical literacy, data confidentiality and statistical disclosure, Geographic Information Systems (GIS) and spatial data, as well as publication, annotation, curation and authentication of networked knowledge assets. For other key topics see previous IASSIST Conferences at $<$ http://www.iassistdata.org/conferences/index.html>.

\title{
About IASSIST
}

IASSIST is an international organization of professionals working in and with information technology and data services to support research and teaching in the social sciences. The organization also explores issues of access, stewardship and the interconnections among social science, behavioral, biological, and health data. Typical workplaces include quantitative and qualitative data archives/libraries, statistical agencies, research centers, libraries, academic departments, government departments, and non-profit organizations. See the IASSIST website at $<\mathrm{http}: / / \mathrm{www}$.iassistdata.org $>$ for further information.

IASSIST conferences bring together data professionals, data producers, and data analysts from around the world for presentations and workshops covering new and persistent issues relating to access to data, its documentation, and digital preservation, with special emphasis on the social sciences. The social sciences have a long history of data sharing activity which will make the conference of interest to colleagues in disciplines where improving data access practices is on the policy agenda, and where there are clear overlaps with digital curation, data publishing, e-science/ cyberinfrastructure initiatives, and new interdisciplinary collaborations.

The IASSIST Quarterly (IQ), available online from the IASSIST website and in print, is another important means of communication for the data community. Each year, IQ features the papers associated with conference presentations. Of special note is the IASSIST Publication Award, involving a cash prize for the winning paper. For further details see: <http://www.iassistdata.org/publications/pubaward.html >.

The IASSIST Outreach Committee accepts applications from data professionals in countries with emerging economies for funding to attend IASSIST 2006. More information about the Outreach Committee's work, including funding criteria and online application form, can be found at $<\mathrm{http}: / / \mathrm{www}$.iassist.ucdavis.edu/> 


\section{IASSIST 2006}

\section{Procedure}

The deadline for paper, session, and poster/demonstration proposals is 16th January 2006. The Conference Program Committee will send notification of the acceptance of proposals on or before 10th February 2006.

Individual presentation proposals and session proposals are welcome. Proposals for complete sessions, typically a panel of three to four presentations within a 90-minute session, should provide information on the focus of the session, the organizer or moderator, and possible participants. The session organizer or moderator will be responsible for securing session participants, some of whom may submit paper proposals independently.

All proposals, including proposed title and an abstract (recommended length 150 words), should be submitted using the link on the following website:

$<$ http://www.icpsr.umich.edu/iassist/call.html>

Alternatively, proposals may be sent via email to <iassist06@gmail.com>. In this case, please use a subject heading of "Paper proposal - Your Name" or "Session proposal - Your Name" replace "Your Name" with the name of the session organizer.

Further information on travel and accommodations will be available at links from the IASSIST '06 Conference website: <http://www.icpsr.umich.edu/iassist/>. Online registration is scheduled to open on 1st February 2006.

Make plans to come to Ann Arbor for the IASSIST 2006 Conference May 22-26, 2006 